\title{
Open-Channel Block of N-Methyl-D-Aspartate (NMDA) Responses by Memantine: Therapeutic Advantage against NMDA Receptor- mediated Neurotoxicity
}

\author{
Huei-Sheng Vincent Chen, ${ }^{1}$ James W. Pellegrini, ${ }^{1}$ Sanjay K. Aggarwal,' Sizheng Z. Lei, ${ }^{1}$ Steven Warach, ${ }^{1,2,3}$ \\ Frances E. Jensen, ${ }^{1,3}$ and Stuart A. Lipton ${ }^{1,2,3,4}$ \\ Laboratory of Cellular and Molecular Neuroscience, Department of Neurology, 'Children's Hospital, the Departments of \\ Neurology, ${ }^{3}$ Beth Israel Hospital, ${ }^{3}$ Brigham and Women's Hospital, ${ }^{4}$ Massachusetts General Hospital, and the ${ }^{4}$ Program in \\ Neuroscience, Harvard Medical School, Boston, Massachusetts 02115
}

\begin{abstract}
Excessive activation of NMDA receptors is thought to mediate the calcium-dependent neurotoxicity associated with hypoxic-ischemic brain injury, trauma, epilepsy, and several neurodegenerative diseases. For this reason, various NMDA antagonists have been investigated for their therapeutic potential in these diseases, but heretofore none have proven to be both effective and safe. In the present study, memantine, an adamantane derivative similar to the antiviral drug amantadine, is shown to block the channels activated by NMDA receptor stimulation. From whole-cell and singlechannel recording experiments, the mechanism of action of memantine is deduced to be open-channel block, similar to MK-801; however, unlike MK-801, memantine is well tolerated clinically. Compared to MK-801, memantine's safety may be related to its faster kinetics of action with rapid blocking and unblocking rates at low micromolar concentrations. Furthermore, at these levels memantine is an uncompetitive antagonist and should theoretically allow near-normal physiological NMDA activity throughout the brain even in the face of pathologically high focal concentrations of glutamate. These pharmacological properties confer upon memantine a therapeutic advantage against NMDA receptor-mediated neurotoxicity with few side effects compared with other organic NMDA open-channel blockers. Moreover, memantine is increasingly effective against escalating lovels of glutamate, such as those observed during a stroke. Low micromolar concentrations of memantine, levels known to be tolerated by patients receiving the drug for the treatment of Parkinson's disease, prevent NMDA receptor-mediated neurotoxicity in cultures of rat cortical and retinal
\end{abstract}

\footnotetext{
Received Apr. 16, 1992; revised June 8, 1992; accepted June 10, 1992.

We are grateful to Dr. J. Bormann for helpful discussions and for the gift of memantine (Merz and Co., Frankfurt, Germany). We also thank Drs. Philip Stieg and Sumir Sathi for help with the stroke model experiments and Sara Vasquez for expert technical assistance. H.-S.V.C. was supported by a Ryan Fellowship. This research was conducted while S.Z.L. was a CIBA/ARVO Postdoctoral Fellow. S.A.L. is a recipient of an Established Investigator Award from the American Heart Association. This work was supported by NIH Grants EY05477, EY09024, and NS07264 and by a grant from the Sunny von Bulow Coma and Head Trauma Research Foundation. This work was completed in partial fulfillment by H.S.V.C. of the requirements of a Ph.D. degree in the Department of Biological Chemistry and Molecular Pharmacology at Harvard Medical School.

Correspondence should be addressed to Dr. Stuart A. Lipton, Harvard Long wood Neurology Program, Enders Building, Suite 361, 300 Longwood Avenue Boston, MA 02115.

Copyright (C) 1992 Society for Neuroscience $0270-6474 / 92 / 124427-10 \$ 05.00 / 0$
}

ganglion cell neurons; memantine also appears to be both safe and effective in a rat stroke model. These results suggest that memantine has considerable therapeutic potential for the myriad of clinical entities associated with NMDA receptor-mediated neurotoxicity.

Excessive levels of glutamate, or related congeners, are thought to be associated with neuronal cell death in hypoxic-ischemic brain injury, epilepsy, trauma, and several degenerative neurological disorders such as Huntington's disease, Parkinsonism, and HIV-1-associated cognitive/motor complex (AIDS dementia) (reviewed in Rothman and Olney, 1987; Choi, 1988; Meldrum and Garthwaite, 1990; Lipton, 1992). In many areas of the CNS, the predominant form of this neurotoxicity appears to be mediated by activation of the NMDA subtype of glutamate receptor and subsequent influx of excessive $\mathrm{Ca}^{2}$. There is some evidence that NMDA open-channel blockers rather than competitive receptor antagonists may prove more useful in combatting the damage engendered by escalating levels of glutamate such as that observed following a stroke (Levy. and Lipton, 1990). One type of NMDA open-channel blocker is MK-801 (dizocilpine) (Huettner and Bean, 1988), which has been shown to protect neurons from ischemic necrosis in gerbils and rats (Foster et al., 1988). However, this type of dissociative anesthetic also impairs many normal neuronal functions and can cause injury or reversible neuronal swelling at therapeutic concentrations (Olney et al., 1989). In contrast, we now report that another drug, memantine, which is known to be well tolerated clinically, is an NMDA open-channel blocker and uncompetitive antagonist. At least part of memantine's safety, compared to that of MK-801, may possibly be attributed to its unique rapid-response kinetics, which should allow substantial NMDA receptor function even in areas of potentially damaged neurons.

Memantine (1-amino-3,5-dimethyladamantane hydrochloride) is known to have anti-Parkinsonian (Schneider et al., 1984) and anti-epileptic (Meldrum et al., 1986) properties and is an analog of amantadine ( 1 -adamantanamine hydrochloride), a wellknown antiviral agent (Zlydnikov et al., 1981). Both adamantane derivatives have been used clinically for Parkinson's disease for many years in the United States or in Europe (Schwab et al., 1969; Schneider et al., 1984). Recently, memantine was reported to block NMDA-evoked current in embryonic mouse spinal neurons (Bormann, 1989). In the present study, we describe the molecular mechanism of memantine action and report 
that low micromolar concentrations, levels known to be therapeutic in Parkinson's discasc (Wescmann ct al., 1980, 1983), prevent NMDA receptor-mediated neurotoxicity in both rat retinal ganglion cell and cortical neurons.

\section{Materials and Methods}

Cell culture. For retinal ganglion cell labeling, dissociation, and culture, we used techniques that have been detailed elsewhere (Leifer et al., 1984). Briefly, retinal ganglion cells of 4-6-d-old Long-Evans rats were retrogradely labeled with granular blue by injection in the superior colliculus and retrograde transport. Two to six days later, the animals were killed by decapitation. Following enucleation, the retinas were dissociated with mild treatment with the enzyme papain. The retinal cells were then plated onto glass coverslips coated with poly-L-lysine in 35 $\mathrm{mm}$ tissue culture dishes. The growth medium was Eagle's minimum essential medium supplemented with $0.7 \%(\mathrm{w} / \mathrm{v})$ methylcellulose, $0.3 \%$ (w/v) glucose, $2 \mathrm{mM}$ glutamine, $5 \%(\mathrm{v} / \mathrm{v})$ rat serum, and $1 \mu \mathrm{g} / \mathrm{ml}$ gentamicin. Retinal ganglion cells were identified by the presence of the retrogradely transported dye granular blue.

For the experiments with rat cortical cultures, cells were derived from embryonic (fetal day 15) Sprague-Dawley rats as described previously (Dichter, 1978; Rosenberg and Aizenman, 1989). Following dissociation in $0.027 \%$ trypsin, cerebral cortical cells were plated at a density of $4.5 \times 10^{5}$ per $35 \mathrm{~mm}$ dish containing poly-L-lysine-coated glass coverslips in Dulbecco's modified Eagle's medium with Ham's F12 and heat-inactivated iron-supplemented calf serum (HyClone) at a ratio of $8: 1: 1$, plus $2 \mathrm{mM}$ glutamine, $24 \mathrm{mM}$ HEPES, and $0.23 \%(\mathrm{w} / \mathrm{v})$ penicillinstreptomycin. After $15 \mathrm{~d}$ in culture (when the astrocyte layer had become confluent), the cultures were treated with cytosine arabinoside for 72 $\mathrm{hr}$. The culture medium was replenished three times weekly. Cultures were incubated at $36^{\circ} \mathrm{C}$ in a humidified atmosphere of $5 \% \mathrm{CO}_{2}, 95 \%$ air. The cultures were used for experiments at room temperature (21$24^{\circ} \mathrm{C}$ ) approximately 1 month after plating.

Patch-clamp electrophysiology. Whole-cell and single-channel recordings of rat retinal ganglion cells were performed as described in detail elsewhere (Hamill et al., 1981; Lipton and Tauck, 1987). The neurons were continuously superfused in a chamber at $27-29^{\circ} \mathrm{C}$. with a bath solution composed of (in $\mathrm{mM}$ ) NaCl, $137.6 ; \mathrm{KCl}, 5.8 ; \mathrm{CaCl}_{2}, 2.5 ; \mathrm{HEPES}$, 5; glucose, 22.2; with phenol red, $0.001 \%(\mathrm{v} / \mathrm{v})$; glycine, $1 \mu \mathrm{M}$; $\mathrm{pH} 7.2$; and no added magnesium. The patch pipettes were filled with an intracellular solution containing (in $\mathrm{mM}$ ) $\mathrm{CsCl}, 120$; tetraethylammonium chloride, 20; HEPES, 10; EGTA, 2.25; $\mathrm{CaCl}_{2}, 1$; and $\mathrm{MgCl}_{2}, 2$; and sometimes with $3 \mathrm{mM} \mathrm{Mg-ATP}$ to minimize rundown in prolonged recordings ( $\mathrm{pH} 7.2)$. The agonists and antagonists were prepared in bath solution containing $1 \mu \mathrm{M}$ tetrodotoxin (TTX), and they were applied by an array of pneumatic pipettes placed $20-50 \mu \mathrm{m}$ from the neurons. Solution changes could be achieved rapidly, within $50-100 \mathrm{msec}$, by moving the array of constantly flowing pipette tips relative to the cell with a micromanipulator driver. A control pipette containing bath solution and $1 \mu \mathrm{M}$ TTX was used to wash out NMDA-induced current rapidly; occasionally, the NMDA-evoked current was washed out in a slower fashion by the superfusate (as in Fig. 1C).

Measurement of intracellular calcium. Neuronal intracellular free $\mathrm{Ca}^{2+}$ concentration $\left(\left[\mathrm{Ca}^{2+}\right]_{i}\right)$ was analyzed with fura-2 acctoxymethyl ester (Molecular Probes) following published procedures (Grynkiewicz et al., 1985), and using a protocol for digital calcium imaging that has been detailed by this laboratory (Dreyer et al., 1990; Lipton et al., 1991; Sucher and Lipton, 1991). Drugs were administered by bath application or by pneumatic "puffer" pipettes. NMDA $(200 \mu \mathrm{M})$ was always coapplied with glycine $(1 \mu \mathrm{M})$.

Neurotoxicity studies. Rat retinal ganglion cell neurons surviving excitotoxic insult were scored by their ability to take up and cleave fluorescein diacetate to fluorescein as we have described previously (Hahn et al., 1988). In six experiments, we monitored the effect of memantine or amantadine in attenuating NMDA receptor-mediated neurotoxicity of acutely isolated retinal ganglion cells that were cultured for $16-20 \mathrm{hr}$ (Hahn et al., 1988; Levy and Lipton, 1990; Levy et al., 1990; Sucher et al., 1991).

For the neurotoxicity experiments on mixed neuronal and glial cortical cultures, the normal culture medium was exchanged at room temperature for Earle's Balanced Salt Solution (EBSS) without phenol red. Cultures were incubated for $30 \mathrm{~min}$ in NMDA or NMDA plus memantine. The culture medium was then replaced with fresh EBSS and the cultures were returned to the incubator overnight. The next day
( $\sim 18 \mathrm{hr}$ later) the cultures were fixed and scored for neuronal viability, as previously described (Rosenberg and Aizenman, 1989), and verified with $0.2 \%$ trypan blue. Neurons were counted in a masked fashion in $\sim 30$ microscopic fields at $200 \times$.

As an in vivo stroke model, under metofane anesthesia, 7-10-d-old rats underwent bilateral carotid ligation followed by $25 \mathrm{~min}$ of hypoxia in $8 \% \mathrm{O}_{2}$, similar to previously described procedures (Hattori et al., 1989). One-half hour prior to the event, each animal was injected with an intraperitoneal loading dose of $20 \mathrm{mg} / \mathrm{ml}$ memantine (or saline in the case of the controls), and then received memantine maintenance doses of $1 \mathrm{mg} / \mathrm{kg}$ (or saline) at $12 \mathrm{hr}$ intervals. Body temperature was regulated to $32-34^{\circ} \mathrm{C}$ with a water bath. After $48 \mathrm{hr}$, lesion size was measured by magnetic resonance imaging (MRI) with a 4.7 tesla magnetic resonance spectrometer (Bruker Biospec BMT 47/30 MR System). Images were obtained using the following scan parameters: T2 weighted spin-echo images; TR, 2000; TE, 100, field of view, $2 \times 2 \mathrm{~cm}$; slice thickness, $1 \mathrm{~mm}$; acquisition time, $10 \mathrm{~min} 53 \mathrm{sec}$. A computerized analysis of infarct size was performed directly from these images. In addition, following fixation with $4 \%$ paraformaldehyde and embedding in paraffin, the brains were serially sectioned at $20 \mu \mathrm{m}$ and processed for routine histology with hematoxylin and eosin or cresyl violet staining to confirm MRI results.

\section{Results}

Open-channel blockade by memantine of NMDA-evoked whole-cell currents

In our initial experiments, we performed whole-cell recordings with patch electrodes to study the NMDA-evoked current on fluorescently labeled, postnatal rat retinal ganglion cells. We chose retinal ganglion cells because these central neurons could be grown in isolation, and thus we could reliably achieve the rapid application of drugs and solution changes that were necessary for the kinetic studies to determine the mode of action of memantine. Work on retinal ganglion cell neurons (Aizenman et al., 1988, 1989; Karschin et al., 1988) had revealed the presence of NMDA-evoked currents that were pharmacologically similar to other central neurons (MacDonald and Nowak, 1990). We found that $12 \mu \mathrm{M}$ memantine effectively inhibited $200 \mu \mathrm{M}$ NMDA-activated currents at a holding potential of $-50 \mathrm{mV}$ $(88 \pm 1 \%$ block, mean $\pm \mathrm{SEM} ; n=11)$ (Fig. $1 A$, left). The degree of block was voltage dependent, manifesting considerably less inhibition at $+50 \mathrm{mV}(28 \pm 1 \%$ block; $n=8)$ (Fig. $1 \mathrm{~A}$, right). Steady-state inhibition by memantine was attained within $1 \mathrm{sec}$ of drug application and was agonist dependent; that is, blockade only occurred in the presence of NMDA (Fig. $1 B$, left). In addition, among excitatory amino acid (EAA) receptors, the action of memantine was relatively specific for the NMDA subtype; kainate $(50 \mu \mathrm{M})$ - and quisqualate $(5 \mu \mathrm{M})$-evoked currents were not affected by $12 \mu \mathrm{M}$ memantine (Fig. $1 B$, right). The voltage and agonist dependencies of memantine antagonism are consistent with a mechanism of open-channel block (Huettner and Bean, 1988; Sernagor et al., 1989).

The dissociation time constant of memantine from NMDA receptor channels was approximately $5.2 \mathrm{sec}$ at $-60 \mathrm{mV}$ in the continued presence of NMDA (Fig. $1 C$, right). This slow unblocking phase was no longer observed after preexposure to 3 $\mathrm{mM}$ magnesium [a fast open-channel blocker of these NMDA receptor-operated ion channels (reviewed in MacDonald and Nowak, 1990)] (Fig. 1C, left). These findings suggest a blocking site of memantine that is possibly inside the channcl pore, close to or interacting with $\mathrm{Mg}^{2+}$ binding site. In a competitive binding study using postmortem human brain homogenates, memantine was recently found to inhibit the binding of tritiated MK-801 (Kornhuber et al., 1989), also consistent with a mode of action within the channel pore. 

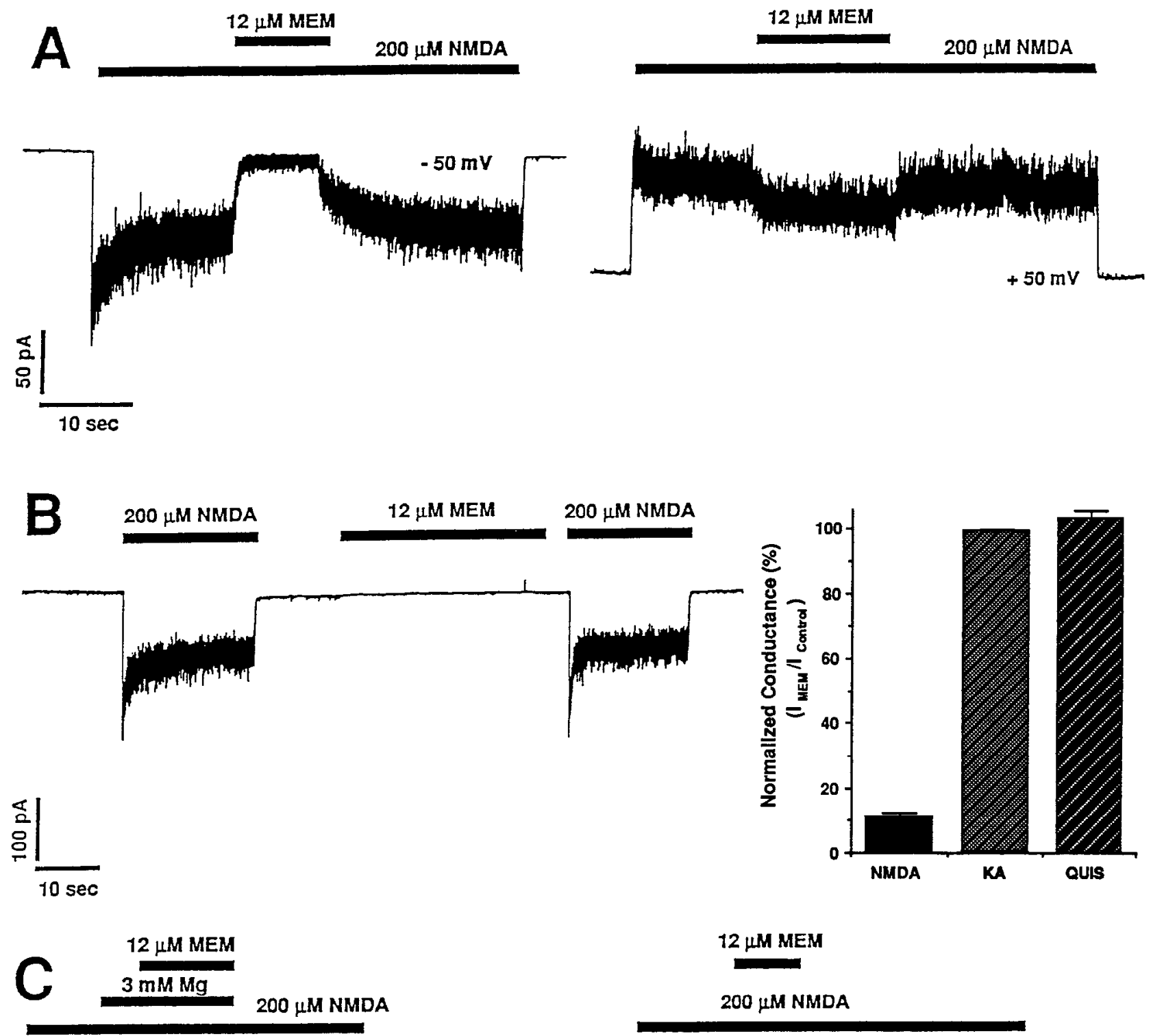

\section{$12 \mu M M E M$}

200 HM NMDA

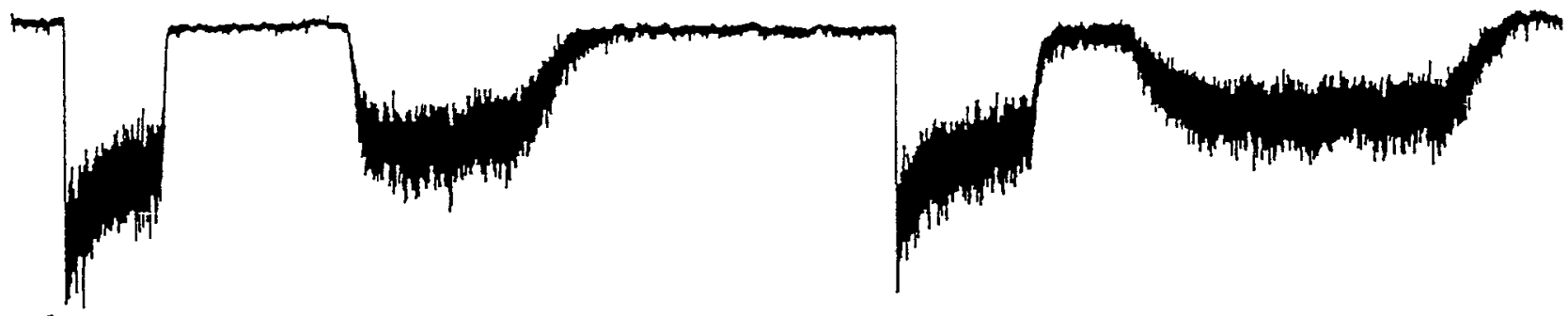

离

$$
10 \mathrm{sec}
$$

Figure 1. Evidence for open-channel block of NMDA-elicited whole-cell current by memantine ( $M E M)$ on rat retinal ganglion cells. $A$, Blocking effect of $12 \mu \mathrm{M}$ memantine on $200 \mu \mathrm{M}$ NMDA-induced current at holding potentials of -50 and $+50 \mathrm{mV}$ in whole-cell recordings. $B$, Lack of effect on $200 \mu \mathrm{M}$ NMDA-induced current of $12 \mu \mathrm{M}$ memantine when administered alone at $-60 \mathrm{mV}$ (left). When coapplied with agonist, $12 \mu \mathrm{M}$ memantine did not affect the current elicited by $50 \mu \mathrm{M}$ kainate $(K A)$ or $5 \mu \mathrm{M}$ quisqualate (QUIS), whereas the response to $200 \mu \mathrm{M}$ NMDA was inhibited by $90 \%$ at $-60 \mathrm{mV}(n=17)($ right $)$. $C$, Removal of $12 \mu \mathrm{M}$ memantine resulted in a slow recovery of NMDA-induced current at -60 $\mathrm{mV}$ (right). This contrasts with the immediate recovery that has been observed following $\mathbf{M g}^{2+}$ block (reviewed by MacDonald and Nowak, 1990 ). Preexposure to $3 \mathrm{mM} \mathrm{Mg}{ }^{2+}$ (left) prior to memantine not only blocked NMDA-induced current but also prevented antagonism by subsequent application of memantine, as evidenced by the absence of slow recovery following washout of both antagonists. A rapid application system was used to administer the drugs, and a fast washout method was used in the experiments shown in $A$ and $B$. 


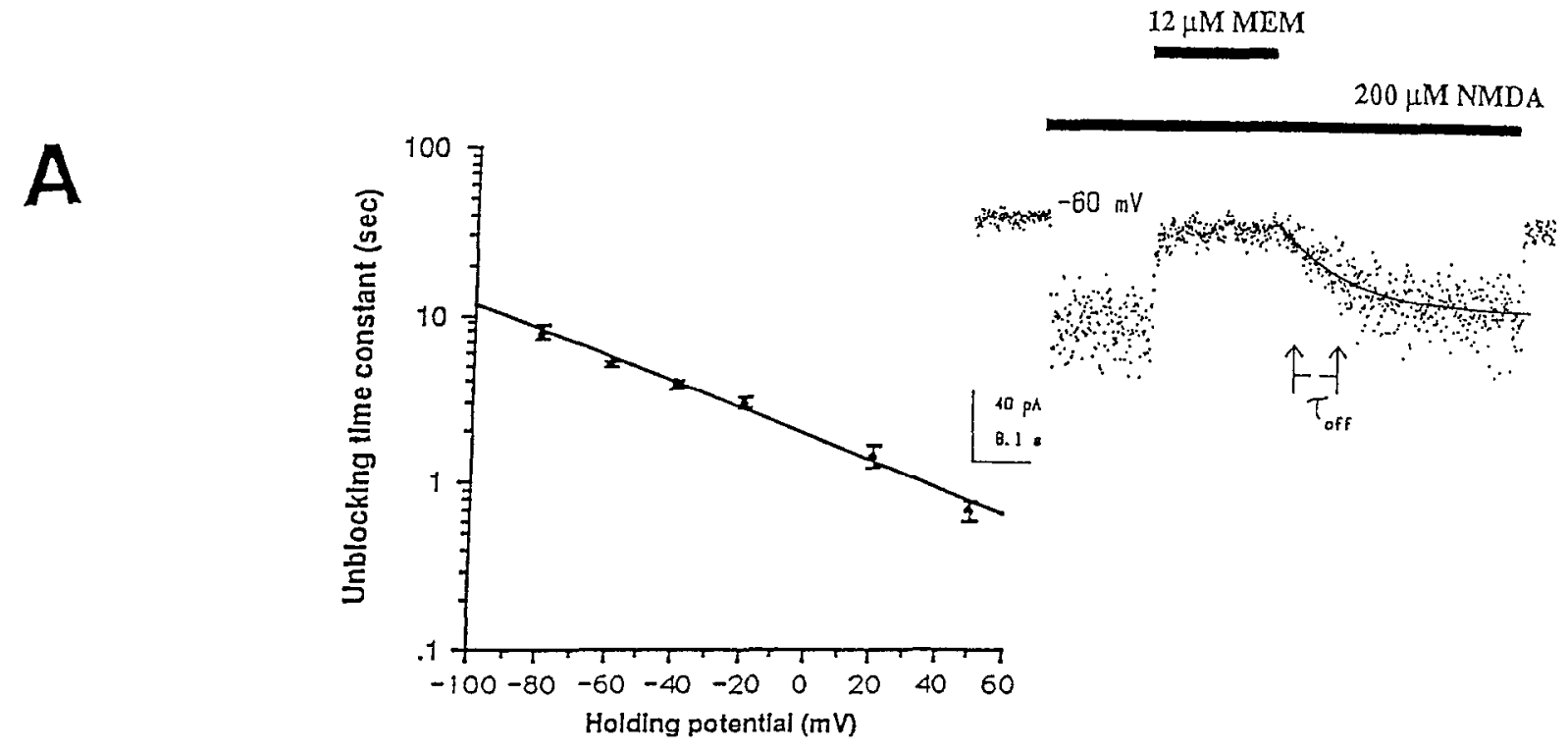

B
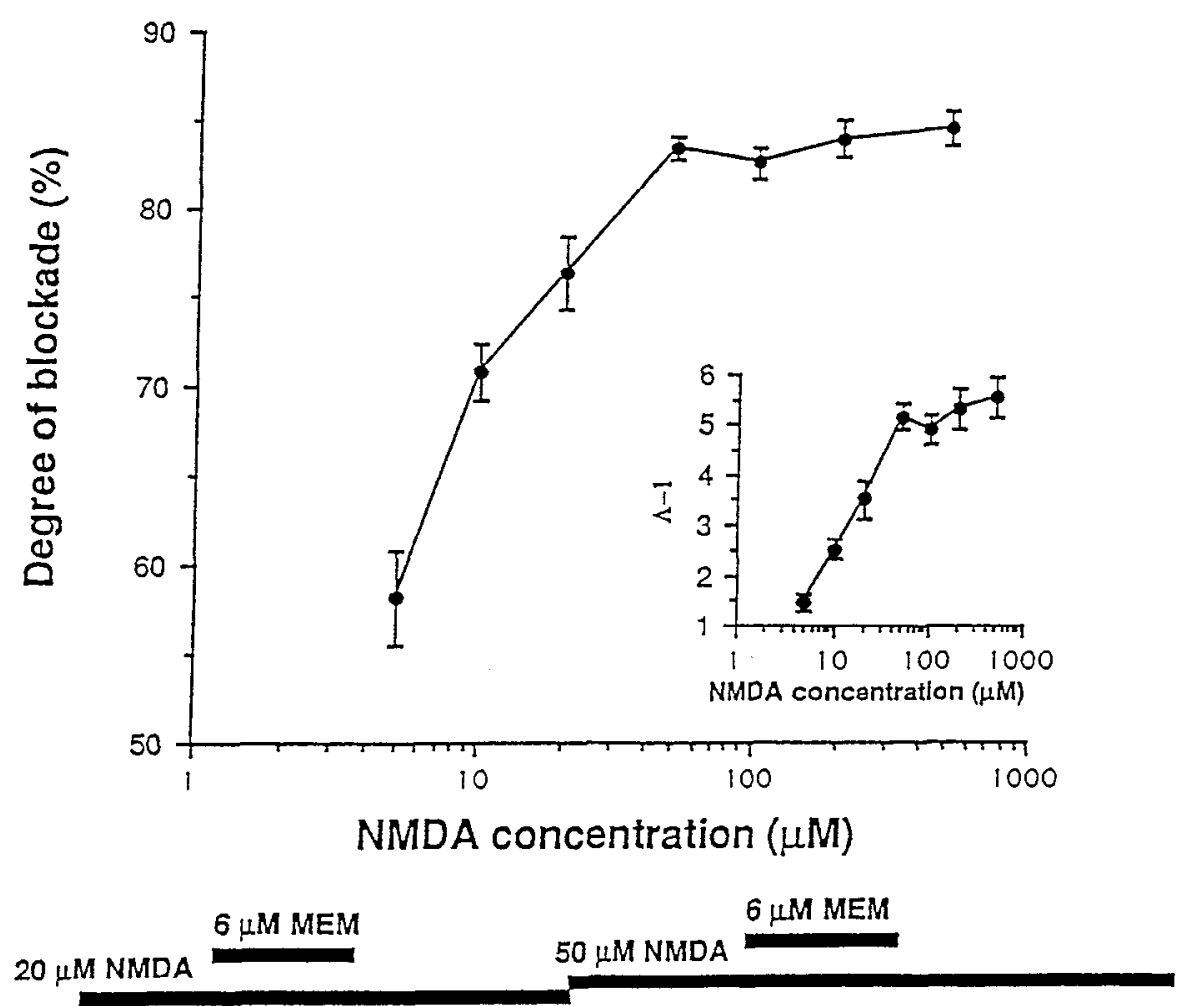

呑|

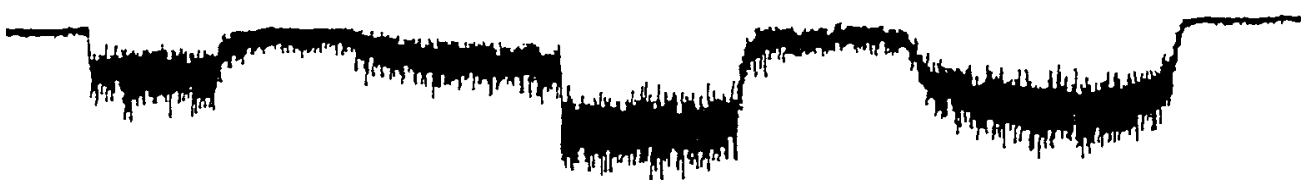

$10 \mathrm{sec}$

Figure 2. Voltage dependence of kinetics and uncompetitive antagonism of memantine $(M E M)$ action on rat retinal ganglion cells. A, Following washout of $12 \mu \mathrm{M}$ memantine, the macroscopic unblocking time constant $\left(\tau_{\mathrm{of}}\right)$ was obtained by fitting a single exponential to the recovery phase of the NMDA-evoked whole-cell current (inset). In the presence of $200 \mu \mathrm{M}$ NMDA, $\tau_{\text {off }}$ was voltage dependent over the range of -80 to $+50 \mathrm{mV}$ (solid line, fit by least squares). $B$, The degree of blockade of NMDA-induced current by $6 \mu \mathrm{M}$ memantine increased with a rising concentration of NMDA. Inset, Transformation of this plot revealed that the value of the response ratio minus $1(\Lambda-1)$ increased with rising NMDA concentration, consistent with a mechanism of uncompctitive antagonism (Ascher et al., 1978, 1979; Rang, 1981). The response ratio $(\Lambda)$ is defined as the amplitude of NMDA-induced current in the absence of memantine divided by the amplitude of this current in the presence of memantine. Bottom, Current 
If indeed memantine plugs the pore of the open NMDA channel, then one would predict that the unblocking or "off" rate for memantine must be influenced by the membrane potential (Huettner and Bean, 1988; Sernagor et al., 1989). Empirically, this prediction has been substantiated. In the presence of 200 $\mu \mathrm{M}$ NMDA, the macroscopic unblocking time constant $\left(\tau_{\mathrm{off}}\right)$ behaves as an exponential function of membrane potential over the range of -80 to $+50 \mathrm{mV}$ (Fig. $2 A$ ). At a holding potential of $-60 \mathrm{mV}, \tau_{\text {orf }}$ is $5.2 \pm 0.2 \sec (n=9)$, while at a holding potential of $+50 \mathrm{mV}, \tau_{\text {off }}$ is $0.7 \pm 0.1 \mathrm{sec}(n=4)$.

The equilibrium dissociation constant $\left(K_{i}\right)$ of memantine is $1.2 \mu \mathrm{M}$ at a holding potential of $-60 \mathrm{mV}$, as measured from the dose-response curve of blockade (H.-S. V. Chen and S. A. Lipton, unpublished observations). The $K_{i}$ of memantine is also voltage dependent when calculatcd with an cquation derived from a simplified model (Ascher et al., 1978, 1979; Rang, 1981):

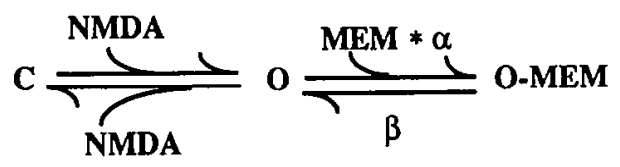

NMDA transforms the closed channels $(C)$ to the open state $(\mathrm{O})$, which is then blocked by memantine (MEM) to form an open, but nonconducting state (O-MEM). The $K_{i}$ is given by

$$
K_{i}=\beta / \alpha,
$$

with $\alpha$ the on-rate constant and $\beta$, the off-rate constant, and

$$
I_{\text {control }} / I_{\text {MEM }}=1+\left([\mathrm{MEM}] / K_{i}\right) /\left(1+K_{d} /[\mathrm{NMDA}]\right) \text {, }
$$

where $I_{\text {control }}$ is the control current amplitude activated by NMDA; $I_{\text {MEM }}$, the NMDA-activated current amplitude in the presence of memantine; and $K_{d}$, the apparent equilibrium dissociation constant for NMDA, which was measured to be $50 \mu \mathrm{M}$ from dose-response curves obtained in our preparation. Equation 2 was then used to calculate the $K_{i}$ of memantine at various membrane potentials. This calculation yielded a $K_{i}$ of $6.1 \mu \mathrm{M}$ at 0 $\mathrm{mV}$ and $1.2 \mu \mathrm{M}$ at $-60 \mathrm{mV}$, which matches the $K_{i}$ measured in the dose-response experiments.

Next, we used the following equation (Woodhull, 1973) to estimate the fraction of the transmembrane field sensed by memantine:

$$
K_{i}=K_{i(0)} \cdot \exp \left(V_{\imath} \delta Z F / R T\right),
$$

where $K_{i(0)}$ is the equilibrium dissociation constant for memantine at a holding potential of $0 \mathrm{mV} ; \delta$, the fraction of the transmembrane potential field for extracellular application of memantine; $V_{t}$, the holding potential; $Z$, the charge of memantine at neutral $\mathrm{pH}$, assumed to be equal to +1 (Schneider et al., $1984)$; and $F, R$, and $T$ have their usual meanings. The blocking site appears to sense approximately $70 \%$ of the transmembrane potential field for the extracellular application of memantine $(\delta$ $=0.71$, calculated by the voltage dependence of $K_{i}$ with the Woodhull model).

\section{Memantine versus other organic NMDA antagonists}

In the case of memantine, the open-channel block represents a type of uncompetitive ${ }^{1}$ inhibition because the NMDA receptoroperated ion channels must be activated, that is, opened, prior to a blocking agent moving into the voltage field of the pore to effect blockade; also, the apparent agonist affinity increases in the presence of antagonist (Chen and Lipton, unpublished observations). In uncompetitive antagonism, the degree of blockade in the presence of a fixed concentration of antagonist should increase with agonist concentration (Ascher et al., 1978, 1979; Rang, 1981). This type of blockade has been observed for memantine in our electrophysiology experiments with acute exposure to NMDA agonists (Fig. $2 B$ and inset). At a holding potential of $-60 \mathrm{mV}, 6 \mu \mathrm{M}$ memantine blocked $\sim 85 \%$ of the current evoked by $200 \mu \mathrm{M}$ NMDA but $<58 \%$ of the current elicited by $5 \mu \mathrm{M}$ NMDA. Furthermore, the absolute amplitude of residual agonist-evoked current during memantine blockade was about the same at different concentrations of NMDA (Fig. $2 B$, bottom current traces). Thus, in the face of escalating levels of EAAs, as observed in ischemia, the proportion of current inhibited by memantine actually increases, yet a basal level of NMDA-evoked response remains, unlike the effects of MK-801, which essentially blocks all NMDA-activated currents at these concentrations for a prolonged period of time (Huettner and Bean, 1988; Karschin et al., 1988). Thus, in the presence of memantine, one might expect that physiological responses to NMDA should be relatively spared irrespective of the concentration of EAAs, permitting persistent receptor function.

These pharmacological properties of memantine appear more advantageous than other organic NMDA open-channel blockers for the treatment of acute NMDA-related neurotoxicity. At -70 $\mathrm{mV}$, the blocking time constant for $10 \mu \mathrm{M}$ MK-801 (probably the most potent NMDA open-channel blocker) is reported to be about $8 \mathrm{sec}$, and the unblocking time constant, $\sim 90 \mathrm{~min}$ (Huettner and Bean, 1988). At this concentration [about 1001000 -fold above the reported $K_{i}$ of $10-30 \mathrm{nM}$ (Wong et al., 1986; Foster and Wong, 1987)], MK-801 blocks $90-99 \%$ of NMDA-evoked currents even at NMDA concentrations as low as $5 \mu \mathrm{M}$. This high degrec of blockade would allow only minimal basal glutamatergic neurotransmission in areas with normal glutamate levels and would thus result in untoward side effects. If, on the other hand, the high degree of NMDA blockade is avoided by lowering the dose of MK-801, the blocking rate would become extremely slow and might not be effective in the prevention of acute glutamate neurotoxicity mediated by excessive NMDA receptor activation. In addition, the unblocking rate of MK-801 is much slower than memantine; hence, if side effects occur, a much longer time period is required to wash out MK-

\footnotetext{
We do not discount the possibility, however, that long-term incubations (many hours) with memantine and very low concentrations of agonist could also result in a component of noncompetitive inhibition; under these conditions, memantine might bind to closed NMDA receptor-operated channels after entering through a hydrophobic pathway in the membrane.
}

trace at $-60 \mathrm{mV}$ induced by 20 and $50 \mu \mathrm{M}$ NMDA illustrates that the relative degree of blockade by memantine was greater for the higher concentration of agonist. The degree of current blockade was calculated from the ratio of the steady-state current amplitude during memantine application relative to the steady-state current induced by NMDA alone just prior to memantine application. A rapid application and washout method system was used to administer the drugs. 

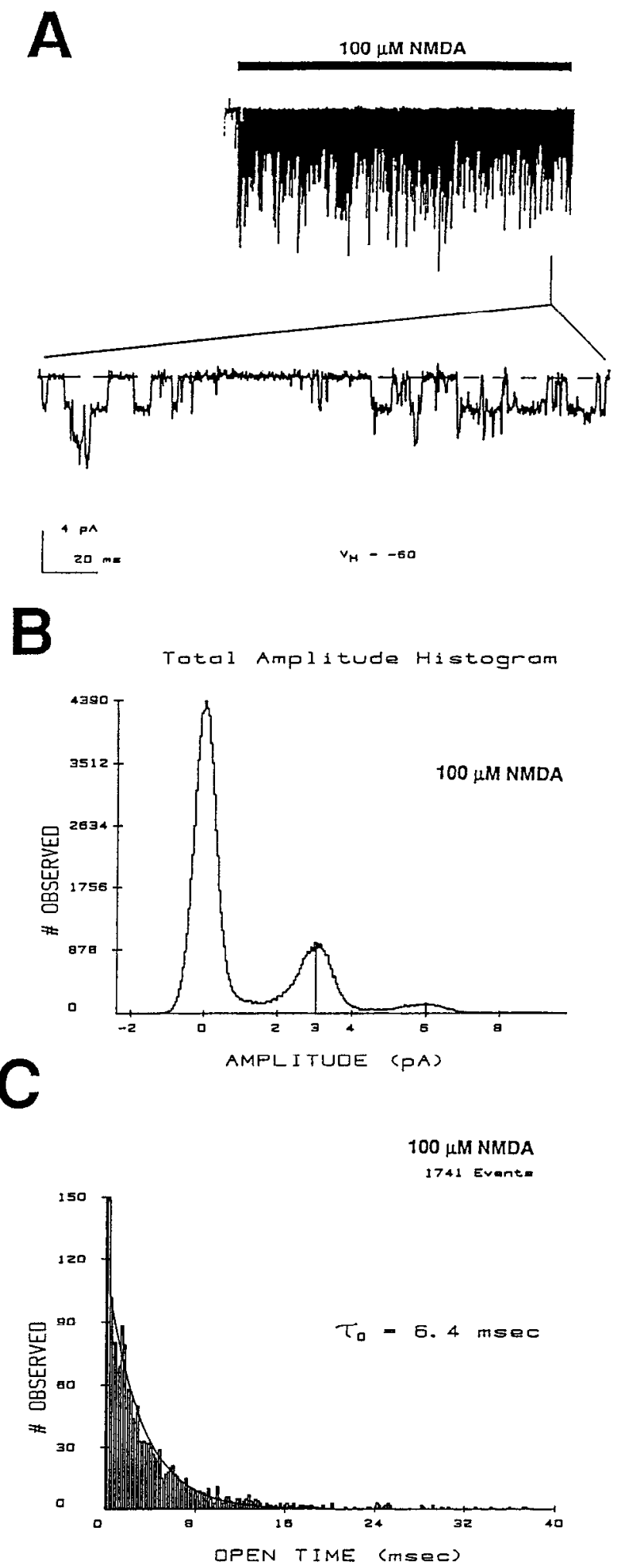
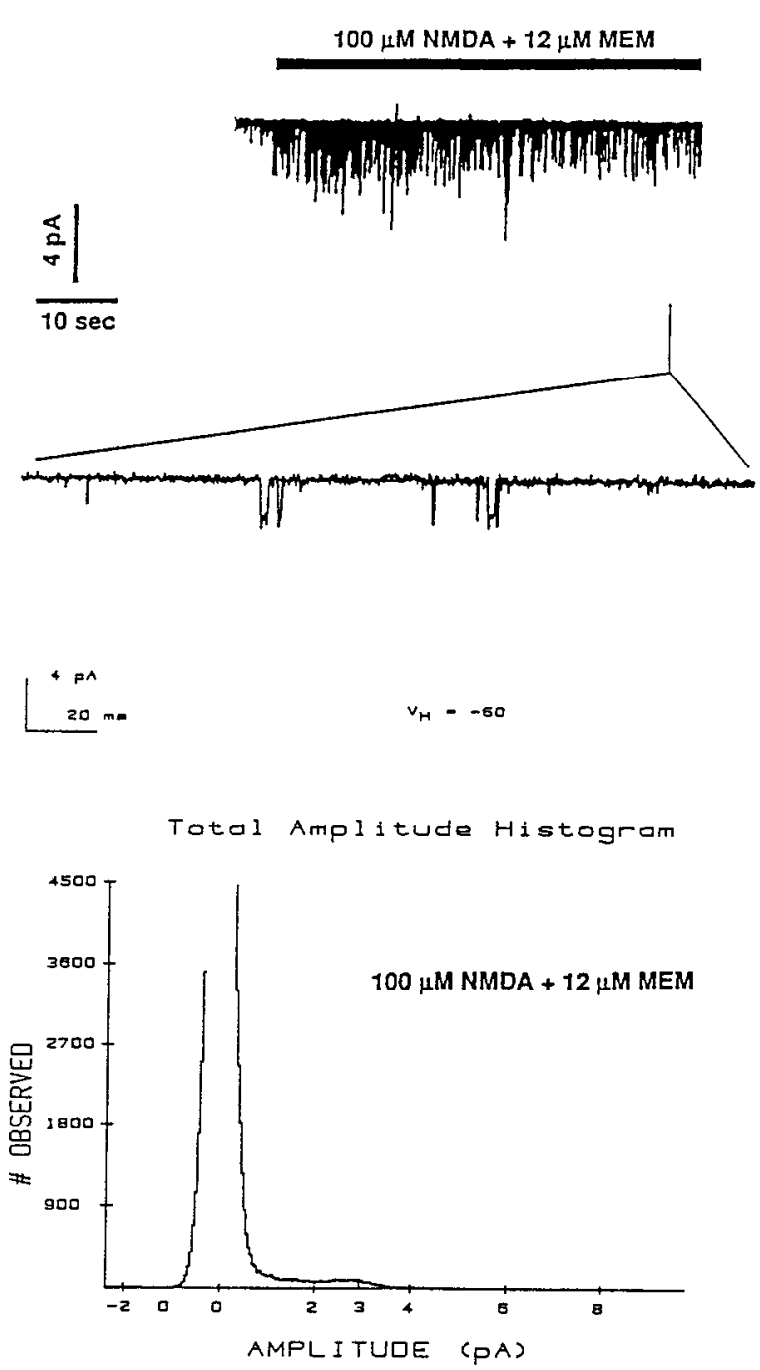

$100 \mu M$ NMDA + $12 \mu M$ MEM

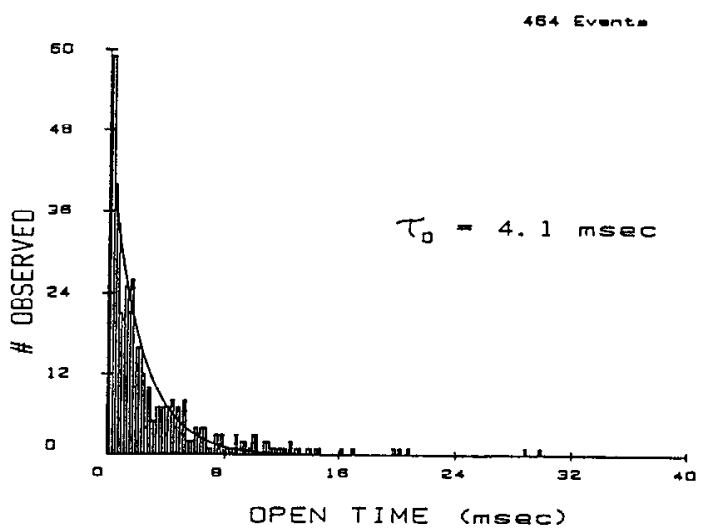

Figure 3. Memantine (MEM) blocks single-channel activity in outside-out patches from rat retinal ganglion cells. $A$, Single-channel activity elicited in a multichannel patch by $100 \mu \mathrm{M}$ NMDA (left) and by simultaneous application of $100 \mu \mathrm{M}$ NMDA plus $12 \mu \mathrm{M}$ memantine (right) at a holding potential of $-60 \mathrm{mV}$. Filtered at $5 \mathrm{kHz}$; digitization rate, $50 \mu \mathrm{sec}$; for recording conditions, see Materials and Methods. $B$, Total amplitude histogram for patch in $(A)$. Histograms were constructed (with a bin size of $0.04 \mathrm{pA}$ ) from a $4.9 \mathrm{sec}$ epoch for control (left) and 6.6 sec for memantine (right), beginning about $30 \mathrm{sec}$ after the application of each solution. This delay ensured that channel activity approached steady state. The memantine record was longer in order to obtain a discernible number of events. Patch 201 . $C$, Open-time histograms. To improve analysis, another patch (patch 207) was used containing very few overlapping events. Data were analyzed with idealized records by using a half-amplitude threshold criterion (Colquhoun and Sigworth, 1983). As a first approximation to the study of the mechanism of memantine blockade, we did not attempt to resolve subconductance states, which would have complicated the analysis (Howe et al., 1991). To avoid these complications, wc chose this patch because it had less subconductance transitions from the major conductance state of $45 \mathrm{pS}$. Data for the control histogram (left) were collected for 
801 from the brain. Compared with other NMDA open-channel blockers, including ketamine, phencyclidine, and tricyclic antidepressants (Mayer et al., 1988; Wong and Kemp, 1991), the faster kinctics of action of low micromolar memantine, coupled with a $K_{i}$ of $\sim 1-2 \mu \mathrm{M}$ at the resting potential, make this a relatively advantageous drug for the prevention of NMDA-related neurotoxicity.

\section{Open-channel blockade by memantine of NMDA-evoked single-channel currents}

To demonstrate conclusively that the mode of action of memantine was open-channel block, we also performed singlechannel recordings. We found that $12 \mu \mathrm{M}$ memantine blocked NMDA-evoked single-channel activity in outside-out patches. Application of $100 \mu \mathrm{M}$ NMDA activated a burst of channel activity (Fig. $3 A$, left). In conjunction with $12 \mu \mathrm{M}$ memantine, however, $100 \mu \mathrm{M}$ NMDA elicited only an initial burst of openings followed by decreasing channel activity (Fig. $3 \mathrm{~A}$, right). The unitary channel conductance was not changed for the major amplitude of events ( $45 \mathrm{pS}$ for this patch). The frequency of channel opening was reduced by $\sim 87 \%$ in the presence of memantine but never totally disappeared (Fig. $3 B$ ). The events were also briefer after memantine application, consistent with blockade of open channels. A single exponential fit to the open time histogram revealed that the time constant $\left(\tau_{o}\right)$ was reduced from $6.4 \mathrm{msec}$ to $4.1 \mathrm{msec}$ by memantine (Fig. 3C), and recovered to $6.5 \mathrm{msec}$ after antagonist washout. Initially, it may appear surprising that $\tau_{o}$ did not decrease to a greater degree. However, at a concentration of $12 \mu \mathrm{M}$ memantine, the on rate of antagonist, calculated from macroscopic observations of $K_{i}$ and $\tau_{\text {off }}$, is relatively slow compared to the channel closing rate (from Eqs. 1, 2; on-rate constant, $\alpha \approx 1 \times 10^{5} \mathrm{M}^{-1} \mathrm{sec}^{-1}$ at $-60 \mathrm{mV}$; closing rate $\approx 100-200 \mathrm{sec}^{-1}$ ). This results in $\tau_{o}$ being only somewhat shorter. In fact, at low micromolar concentrations of memantine, it is the decrease in opening frequency that accounts mainly for the reduction of macroscopic current. Taken together, the results of the single-channel and whole-cell recordings suggest that memantine selectively inhibits NMDA-elicited current by a mechanism of open-channel block.

\section{Memantine attenuates $N M D A$-induced $\left[\mathrm{Ca}^{2}\right]_{\mathrm{i}}$ responses}

In parallel experiments, we found that memantine inhibited NMDA-evoked $\left[\mathrm{Ca}^{2 \dagger}\right]_{i}$ responses. Early increases in $\left[\mathrm{Ca}^{2+}\right]_{i}$ are thought to be associated with delayed-onset NMDA receptormediated neurotoxicity (reviewed by Choi, 1988). With digital calcium imaging techniques, $6 \mu \mathrm{M}$ memantine largely prevented the excessive influx of calcium elicited by $200 \mu \mathrm{M}$ NMDA (Fig. 4). In fact in the presence of memantine, $\left[\mathrm{Ca}^{2+}\right]_{i}$ rose only to levels associated with a low degree of NMDA receptor stimulation. This result further supports the premise that memantine allows basal NMDA receptor-mediated responses but blocks excessive NMDA-croked activity.

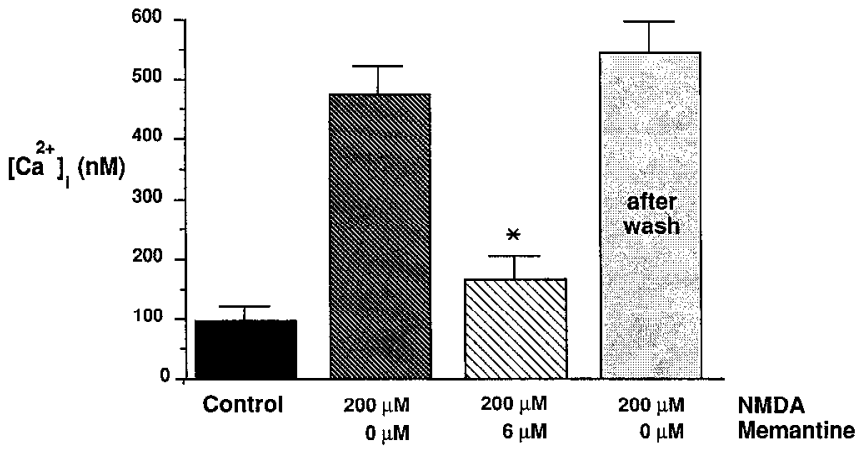

Figure 4. Memantine attenuates NMDA-evoked $\left[\mathrm{Ca}^{2+}\right]_{i}$ responses in retinal ganglion cell neurons. In a bath solution with no added magnesium, $200 \mu \mathrm{M}$ NMDA elicited large increases in $\left[\mathrm{Ca}^{2+}\right]_{i}$ Memantine $(6 \mu \mathrm{M})$ significantly decreased the $\left[\mathrm{Ca}^{2+}\right]_{i}$ response to NMDA. Values represent mean and SEM, $n=12{ }^{*}$ indicates that the NMDA-evoked change in $\left[\mathrm{Ca}^{2+}\right]$, was significantly less than the initial NMDA response $(p<0.01$, with an ANOVA followed by a Scheffe multiple comparison of means). Similar results were observed when $200 \mu \mathrm{M}$ amantadine was used instead of $6 \mu \mathrm{M}$ memantine (not shown).

\section{Memantine ameliorates $N M D A$ receptor-mediated neurotoxicity in vitro and in vivo}

In neurotoxicity experiments on cultures of both rat retinal ganglion cells and cortical neurons, $6-12 \mu \mathrm{M}$ memantine prevented NMDA receptor-mediated neuronal injury (Fig. 5A-C). As described elsewhere (Hahn et al., 1988; Levy and Lipton, 1990; Levy et al., 1990; Sucher et al., 1991), in the retinal preparation an endogenous glutamate-like agonist produces neurotoxicity in the presence of elevated extracellular calcium and low magnesium concentrations (compare Fig. $5 A, B$, columns 1,2 ). This form of neuronal cell death is mediated by activation of the NMDA receptor because the NMDA-specific antagonists $D, L$ 2-amino-5-phosphonovalerate $(200 \mu \mathrm{M})$ or MK-801 $(20 \mu \mathrm{M})$ prevented toxicity engendered by the endogenous substance (Hahn et al., 1988; Levy and Lipton, 1990; Levy et al., 1990; Sucher et al., 1991). Memantine also prevented retinal ganglion cell death from the endogenous glutamate-related toxin in a dose-dependent manner, with complete salvage of neurons at $\geq 6 \mu \mathrm{M}$ (Fig. $5 A$ ). The related adamantane, amantadine, can also prevent neurotoxicity, but much higher concentrations are required (Fig. $5 B$ ). The preventive effect of memantine can be generalized to other central neurons since NMDA receptormediated neurotoxicity was also inhibited in mixed cultures of cortical neurons and glia (Fig. 5C). In this case, $12 \mu \mathrm{M}$ memantine completely prevented neuronal death due to a $30 \mathrm{~min}$ incubation in $50 \mu \mathrm{M}$ NMDA. In addition, our in vivo experiments on neonatal rats and the experiments of other workers on adult rats (Seif el Nasr et al., 1990) demonstrate that memantine $(10-20 \mathrm{mg} / \mathrm{kg})$ can protect significantly from forebrain ischemia. For example, in neonatal rats we used MRI analysis

$14.75 \mathrm{sec}$, beginning $20 \mathrm{sec}$ after the initiation of $100 \mu \mathrm{M}$ NMDA. We observed 1754 openings; of these, 1741 events are included in the histogram (bin width, $200 \mu \mathrm{sec}$ ). Data for the memantine histogram (right) were collected for $27.85 \mathrm{sec}$, beginning immediately with memantine application. Because memantine drastically decreased the frequency of opening, this strategy was necessary to ensure sufficient events for analysis. For memantine, all 464 openings observed are included in the histogram. The value for the mean open time was estimated from the time constant $\left(\tau_{o}\right)$ of the single exponential fit to the open-time histogram (solid line). $\tau_{o}$ is $6.4 \mathrm{msec}$ for control (left) and $4.1 \mathrm{msec}$ during memantine blockade (right). Thus, $\tau_{o}$ was shortened by $36 \%$. When the mean open times were calculated directly by digitally summing the dwell times over the entire record and dividing by the total number of events, similar figures were obtained ( $32 \%$ shortening). Similar results were observed in five patches. 

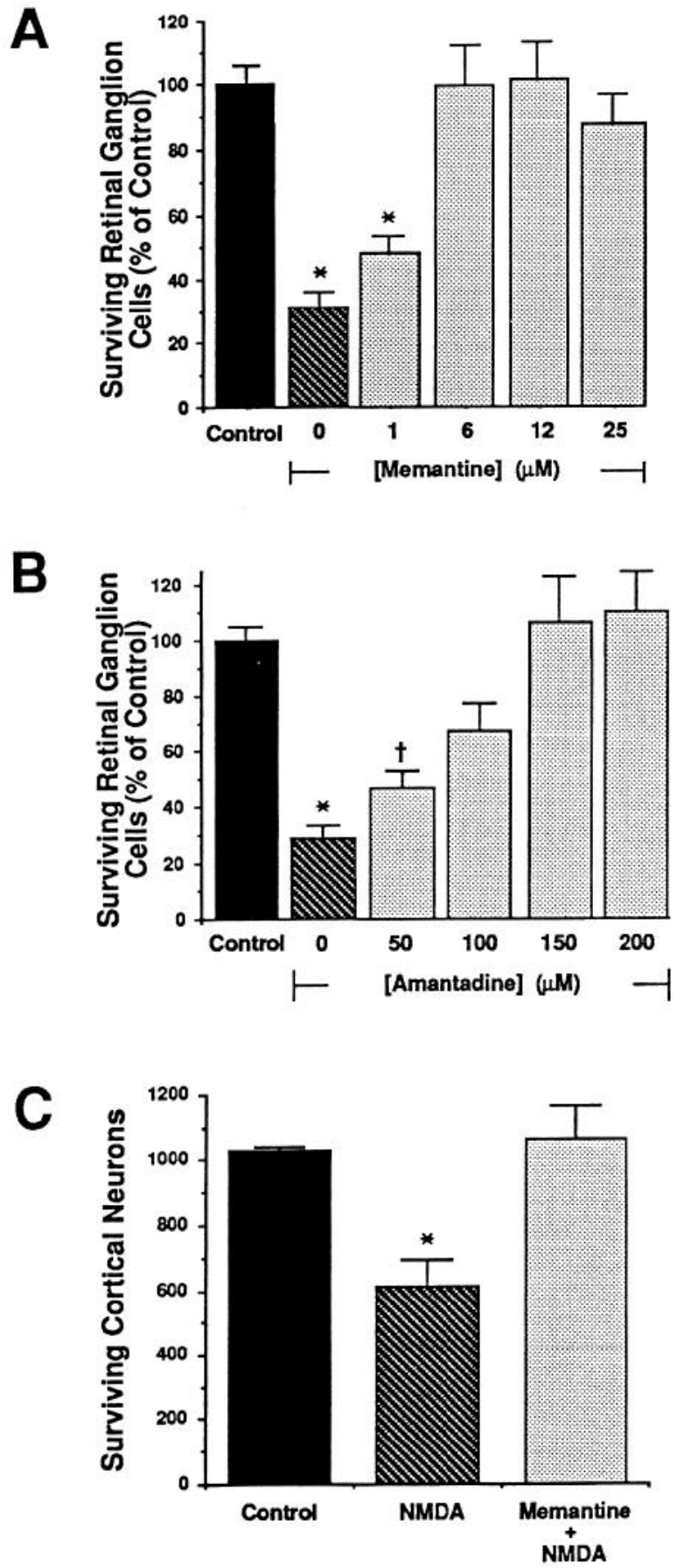

Figure 5. NMDA receptor-mediated neurotoxicity is ameliorated by adamantanes. $A$ and $B$, Surviving retinal ganglion cell neurons as a function of treatment with increasing doses of memantine $(A)$ or amantadine $(B)$. The control dishes contained normal $\mathrm{CaCl}_{2}(1.8 \mathrm{mM})$, while the other categories were exposed to high $\mathrm{Ca}^{2+} / \mathrm{low} \mathrm{Mg}^{2+}(10 \mathrm{mM}$ and $100 \mu \mathrm{M}$, respectively), which facilities NMDA receptor-mediated neurotoxicity in this preparation due to an endogenous glutamate-like agonist (Hahn et al., 1988; Levy and Lipton, 1990; Levy et al., 1990; Sucher et al., 1991). Memantine and amantadine prevented this form of neuronal injury in a dose-dependent manner. The data in each graph represent three separate experiments, each conducted in triplicate and normalized to their respective controls $(\sim 150$ retinal ganglion cells per control dish). $C$, Cortical neurons exposed to $50 \mu \mathrm{M}$ NMDA are protected by $12 \mu \mathrm{M}$ memantine. Cortical cultures were scored for neurotoxicity as reported (Rosenberg and Aizenman, 1989). Experiments were performed in triplicate and on separate days. The values shown represent mean and SEM. An ANOVA was used to test for significance followed
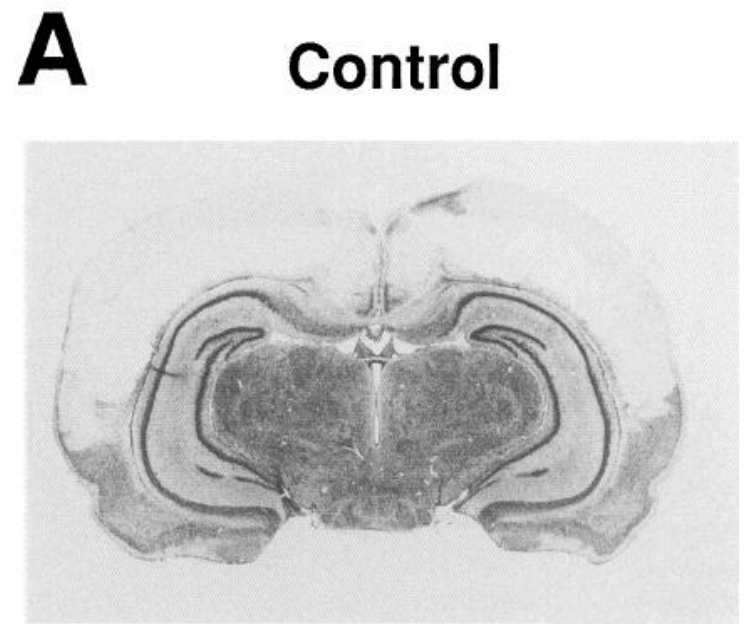

\section{B Memantine Treated}

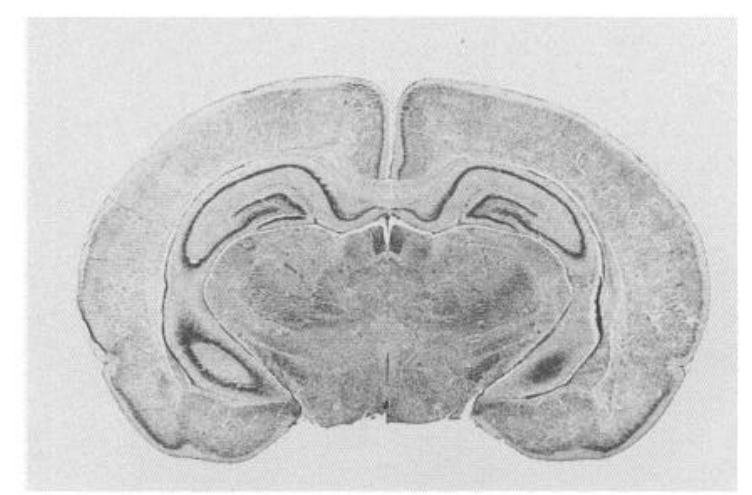

Figure 6. Memantine ameliorates hypoxic-ischemic brain damage following bilateral carotid occlusion and hypoxia. Coronal sections of 9$\mathrm{d}$-old rat brains obtained $2 \mathrm{~d}$ following stroke. $A$, Representative control brain, which received only saline injections, sustained large, bilateral cortical infarcts with some involvement of underlying hippocampal structures. $B$, Brain treated with a $20 \mathrm{mg} / \mathrm{kg}$ loading dose of memantine followed by maintenance doses of $1 \mathrm{mg} / \mathrm{kg} / 12 \mathrm{hr}$ was relatively protected from damage. Based upon brain tissue concentration and elimination rate (Wesemann et al., 1983), this dosing regimen resulted in a steadystate brain parenchymal level of $\approx 10 \mu \mathrm{M}$. Hematoxylin and eosin stain.

to assess the size of large cerebral infarcts, defined as $\approx 50 \%$ forebrain injury in control animals $2 \mathrm{~d}$ post insult; memantine $(20 \mathrm{mg} / \mathrm{kg}$ ) decreased infarct size by $30 \pm 10 \%$ (mean $\pm \mathrm{SEM}$; $n=5$ pairs; $p<0.01$ by Mann-Whitney $U$ test). Histological sections (Fig. 6) verified the protection by memantine in the rat stroke model and closely paralleled the MRI results. Most importantly, in our experiments $20 \mathrm{mg} / \mathrm{kg}$ memantine did not produce lethargy or other behavioral side effects as observed with $1-5 \mathrm{mg} / \mathrm{kg}$ of MK-801 in age- and strain-matched animals. Thus, our findings also have important implications for the action of memantine in preventing neuronal damage in vivo.

by a Scheffé test for multiple comparison of means. ${ }^{*}$ and $\dagger$ indicate significantly less than control value $(p<0.01$ and 0.05 , respectively). 


\section{Discussion}

NMDA receptor-mediated neurotoxicity is thought to comprise a final common pathway in a number of neurologic disease processes. Hence, the demonstration of efficacy of a clinically approved drug in a good stroke model is important, and we demonstrate here that memantine is such an agent. Of equal significance, however, is the capability of using biophysically measured kinetic parameters to predict why one NMDA antagonist is safe in the nervous system while another may not be. This information would possibly allow us to develop even more effective NMDA antagonists to prevent neuronal injury in the face of escalating levels of glutamate or other EAAs. In this study, we show that the kinetic parameters of ion-channel block contribute to the apparent clinical safety of memantine. In the patch-clamp experiments, at a given concentration of memantine, the effects of high concentrations of NMDA were blocked to a relatively greater degree than low concentrations. This mechanism offers both theoretical and practical advantages: the normal consequences of a lower degree of activation of NMDA receptors should be at least partially spared [e.g., the processes involved in eliciting long-term potentiation (LTP), a form of learning and memory]. In contrast, at other sites in the brain, this mode of action would result in concomitant blockade of the lethal effects of escalating levels of glutamate, as observed following a stroke or trauma to the CNS. For example, in the penumbra of a stroke or in the face of ongoing ischemic damage, memantine would produce a greater degree of blockade as the concentration of glutamate increases due to its release from dying neurons.

In the present article on rat central neurons, we describe the effects of adamantane derivatives in producing reversible openchannel block and preventing NMDA receptor-mediated neurotoxicity. Our results show that low micromolar levels of memantine can be neuroprotective in rat models of stroke. These levels compare favorably with therapeutic brain concentrations achieved in Parkinsonian patients receiving the drug (Wesemann et al., 1980, 1983). Such human patients have been treated with memantine for a number of years, generally without serious side effects. The mechanism of action of memantine in Parkinsonism has not been entirely clear. While this article was in preparation, the action of adamantane derivatives in Parkinson's disease was speculated to be due to their NMDA antagonist properties (Turski et al., 1991), and our results are consistent with this suggestion. Since memantine prevents NMDA receptor-mediated neurotoxicity in vitro at these levels and is also effective in animal models of stroke, we suggest that this compound descrves further testing in a variety of clinical neurologic syndromes resulting from excessive stimulation of NMDA receptors. Since drugs in the adamantane class are already used clinically, such testing and application to several human neurologic disorders may be expedited.

\section{References}

Aizenman E, Frosch MP, Lipton SA (1988) Responses mediated by excitatory amino acid receptors in solitary retinal ganglion cells from rat. J Physiol (Lond) 396:75-91.

Aizenman E, Lipton SA, Loring RH (1989) Selective modulation of NMDA responses by reduction and oxidation. Neuron 2:1257-1263.

Ascher P, Marty A, Neild TO (1978) The mode of action of antagonists of the excitatory response to acetylcholine in Aplysia neurones. $\mathbf{J}$ Physiol (Lond) 278:207-235.
Ascher P, Large WA, Rang HP (1979) Studies on the mechanism of action of acetylcholine antagonists on rat parasympathetic ganglion cells. J Physiol (Lond) 295:139-170.

Bormann J (1989) Memantine is a potent blocker of $N$-methyl-Dasparlate (NMDA) receptor channels. Eur J Pharmacol 166:59 1-592.

Choi DW (1988) Glutamate neurotoxicity and diseases of the nervous system. Neuron 1:623-634.

Colquhoun D, Sigworth FJ (1983) Fitting and statistical analysis of single-channel records. In: Single-channel recording (Sakmann B, Neher E, eds), pp 191-263. New York: Plenum.

Dichter MA (1978) Rat cortical neurons in cell culture: culture methods, cell morphology, electrophysiology, and synapse formation. Brain Res 149:279-293.

Dreyer EB, Kaiser PK, Offermann JT, Lipton SA (1990) HIV-1 coat protein neurotoxicity prevented by calcium channel antagonists. Science 248:364-367.

Foster AC, Gill R, Woodruff GN (1988) Neuroprotective effects of MK-801 in vivo: selectivity and evidence for delayed degeneration mediated by NMDA receptor activation. J Neurosci 8:4745-4754.

Foster AC, Wong EHF (1987) The novel anticonvulsant MK-801 binds to the activated state of the $N$-methyl-D-aspartate receptor in rat brain. Br J Pharmacol 91:403-409.

Grynkiewicz G, Phoenie M, Tsien RY (1985) A new generation of $\mathrm{Ca}^{2+}$ indicators with greatly improved fluorescence properties. J Biol Chem 260:3440-3450.

Hahn JS, Aizenman E, Lipton SA (1988) Central mammalian neurons resistant to glutamate toxicity are made sensitive by elevated extracellular calcium: toxicity blocked by the $N$-methyl-D-aspartate antagonist MK-801. Proc Natl Acad Sci USA 85:6556-6560.

Hamill OP, Marty A, Ncher E, Sakmann B, Sigworth FJ (1981) Improved patch-clamp techniques for high resolution current recordings from cells and cell free membrane patches. Pfluegers Arch 391:85100 .

Hattori H, Morin AM, Schwartz PH, Fujikawa DG, Wasterlain CG (1989) Posthypoxic treatment with MK-801 reduces hypoxic-ischemic damage in the neonatal rat. Neurology 39:713-718.

Howe JR, Cull-Candy SG, Colquhoun D (1991) Current through single glutamate receptor channels in outside-out patches from rat cerebellar granule cells. J Physiol (Lond) 432:143-202.

Huettner JE, Bean BP (1988) Block of $N$-methyl-D-aspartate-activated current by the anticonvulsant MK-801: selective binding to open channels. Proc Natl Acad Sci USA 85:1307-1311.

Karschin A, Aizenman E, Lipton SA (1988) The interaction of agonists and noncompetitive antagonists at the excitatory amino acid receptors in rat retinal ganglion cells in vitro. J Neurosci 8:2895-2906.

Kornhuber J, Bormann J, Retz W, Hübers M, Riederer P (1989) Memantine displaces $\left[{ }^{3} \mathrm{H}\right] \mathrm{MK}-801$ at therapeutic concentrations in postmortem human frontal cortex. Eur J Pharmacol 166:589-590.

Leifer D, Lipton SA, Barnstable CJ, Masland RH (1984) Monoclonal antibody to Thy- 1 enhances regeneration of processes by rat retinal ganglion cells in culture. Science 224:303-306.

Levy DI, Lipton SA (1990) Comparison of delayed administration of competitive and uncompetitive antagonists in preventing NMDA receptor-mediated neuronal death. Neurology 40:852-855.

Levy DI, Sucher NJ, Lipton SA (1990) Redox modulation of NMDA receptor-mediated toxicity in mammalian central neurons. Neurosci Lett 110:291-296.

Lipton SA (1992) Models of neuronal injury in AIDS: another role for the NMDA receptor? Trends Neurosci 15:75-79.

Lipton SA, Tauck DL (1987) Voltage-dependent conductances of solitary ganglion cells dissociated from the rat retina. J Physiol (Lond) 385:361-391.

Lipton SA, Sucher NJ, Kaiser PK, Dreyer EB (1991) Synergistic effects of HIV coat protein and NMDA receptor-mediated neurotoxicity. Neuron 7:111-118.

MacDonald JF, Nowak LM (1990) Mechanisms of blockade of excitatory amino acid receptor channels. Trends Pharmacol Sci 11:167172.

Mayer ML, Westbrook GL, Vyklicky L Jr (1988) Sites of antagonist action on $N$-methyl-D-aspartic acid receptors studied using fluctuation analysis and a rapid perfusion technique. $J$ Neurophysiol 60 : 645-663.

Meldrum B, Garthwaite J (1990) Excitatory amino acid neurotoxicity and neurodegenerative disease. Trends Pharmacol Sci 11:379-387.

Meldrum BS, Turski L, Schwarz M, Czuczwar SJ, Sontag K-H (1986) 
Anticonvulsant action of 1,3-dimethyl-5-aminoadamantane. Naunyn Schmiedebergs Arch Pharmacol 332:93-97.

Olney JW, Labruryere J, Price MT (1989) Pathological changes induced in cerebrocortical neurons by phencyclidine and related drugs. Science 244:1360-1362.

Rang HP (1981) Drugs and ionic channels: mechanisms and implications. Postgrad Med J 57[Suppl 1]:89-97.

Rosenberg PA, Aizenman E (1989) Hundred-fold increase in neuronal vulnerability to glutamate toxicity in astrocyte-poor cultures of rat cerebral cortex. Neurosci Lett 103:162-168.

Rothman SM, Olney JW (1987) Excitotoxicity and the NMDA receptor. Trends Neurosci 10:299-302.

Schneider E. Fischer P-A. Clemens R, Balzereit F, Fünfgeld E-W, Haase H-J (1984) Wirkungen oraler Memantin-Gaben auf die Parkinsonsymptomatik. Dtsch Med Woschenschr 109:987-990.

Schwab RS, England AC, Poskanzer PC, Young RY (1969) Amantadine in the treatment of Parkinson's disease. J Am Med Assoc 208: $1168-1170$

Seif el Nasr M, Perucher B, Roßberg C, Mennel H-D, Krieglstein J (1990) Neuroprotective effect of memantine demonstrated in vivo and in vitro. Eur J Pharmacol 185:19-24.

Sernagor E, Kuhn D, Vyklicky L Jr, Mayer ML (1989) Open channel block of NMDA receptor responses evoked by tricyclic antidepressants. Neuron 2:1221-1227.

Sucher NJ, Lipton SA (1991) Redox modulatory site of the NMDA receptor-channel complex: regulation by oxidized glutathione. J Neurosci Res 30:582-591.

Sucher NJ, Aizenman E, Lipton SA (1991) $N$-methyl-D-aspartate antagonists prevent kainate neurotoxicity in rat retinal ganglion cells in vitro. J Neurosci 11:966-971.

Turski L, Bressler K, Rettig K-J, Löschmann P-A, Wachtel H (1991) Protection of substantia nigra from MPP+ neurotoxicity by $N$-methylD-aspartate antagonists. Nature 349:414-418.

Wesemann W, Sturn G, Fünfgeld EW (1980) Distribution and metabolism of the potential anti-Parkinson drug memantine in the human. J Neural Transm [Suppl] 16:143-148.

Wesemann W, Sontag K-H, Maj J (1983) Zur Pharmakodynamik und Pharmakokinetik des Memantin. Arzneimittelforsch/Drug Res 33: $1122-1134$

Wong EHF, Kemp JA (1991) Sites for antagonism on the $N$-methylD-aspartate receptor channel complex. Annu Rev Pharmacol Toxicol 31:401-425.

Wong EHF, Kemp JA, Priestley T, Knight AR, Woodruff GN, Iversen LL (1986) The anticonvulsant MK-801 is a potent $N$-methyl-Daspartate antagonist. Proc Natl Acad Sci USA 83:7104-7108.

Woodhull AM (1973) Ionic blockage of sodium channels in nerve. J Gen Physiol 61:687-708.

Zlydnikov DM, Kubar OI, Kovaleva TP, Kamforin LE (1981) Study of rimantadine in the USSR: a review of the literature. Rev Infect Dis 3:408-420. 